\title{
APRESENTANDO RETRATOS SOCIOLINGUÍSTICOS E DIALETOLÓGICOS DO BRASIL
}

\author{
Sebastião Carlos Leite Gonçalves (UNESP, CNPq) \\ Anna Christina Bentes (UNICAMP)
}

Quando nos dispusemos a organizar o presente volume temático da Alfa - Revista de Linguística, tínhamos em mente um volume que pudesse apresentar à comunidade científica uma fotografia do atual estado da arte dos estudos sociolinguísticos e dialetológicos brasileiros. Tínhamos em mente um volume que fosse representativo dos diversos grupos de pesquisa espalhados pelo território nacional, um volume que reunisse e colocasse em relação os mais importantes resultados de pesquisas sobre a realidade sociolinguística do português brasileiro (PB). Superando nossas expectativas, essa ideia-sonho se concretizou, e, agora, presenteamos o público-leitor com 15 excelentes artigos que, emanados dos principais grupos de pesquisa em Sociolinguística e Dialetologia, revelam a contínua e incessante tarefa de coleta, registro, organização e interpretação de dados linguísticos, e compartilham certa vocação historiográfica, à medida que buscam também situar os leitores sobre o modo como foram sendo construídas as trajetórias de cada grupo.

Nessa apresentação dos artigos aos leitores, nos impusemos a tarefa de também tentar mostrar em que pontos se aproximam e se distanciam as pesquisas e os pesquisadores aqui retratados. Para tanto, o agrupamento dos artigos no volume obedece aos seguintes critérios: primeiramente dispõem-se aqueles que apresentam resultados gerais de pesquisas no interior dos grupos de pesquisa, depois aqueles voltados para questões metodológicas e, por ultimo, os que trazem resultados de fenômenos variáveis específicos.

No primeiro conjunto, estão os artigos representantes dos grupos de pesquisadores do PEUL, do VARSUL, do PORTVIX e do VALCO, ${ }^{1}$ os quais, a partir dos pressupostos centrais da Sociolinguística Variacionista, apresentam resultados de pesquisa ordem mais geral, com base em bancos de fala: no caso do PEUL, ao longo de mais de 30 anos de trabalho, no caso do VARSUL, ao longo de mais de 25 anos de pesquisa; no caso do PORTVIX, há mais de dez anos e, no

Programa de Estudos sobre o Uso da Língua, Projeto Variação Linguística Urbana do Sul, Projeto Português Falado na Cidade de Vitória, Projeto Variação Linguística no Centro-Oeste, respectivamente. 
caso do VALCO, oficialmente, ao longo dos últimos 4 anos. Assim, esses primeiros artigos retratam a longevidade dos três primeiros grupos e o fato de todos eles compartilharem os pressupostos de construção de bancos de dados com base em uma metodologia laboviana, visando a oferecer subsídios para descrição linguística, para testes e desenvolvimentos de teorias linguísticas, para formação de novos pesquisadores e para promoção do conhecimento do $\mathrm{PB}$ e do respeito a suas variedades. Ainda, como parte desse primeiro conjunto, inserem-se três outros artigos complementares entre si, os quais fornecem um panorama do Projeto $\mathrm{ALiB}^{2}$, com informações sobre seus antecedentes, objetivos, metodologia e alguns resultados que permitem construir não só uma visão do estágio atual do desenvolvimento do projeto como também de sua dimensão sociolinguística.

Dois são os artigos que enfocam questões metodológicas, relacionadas principalmente à constituição de amostras representativas de dados linguísticos por meio de entrevistas sociolinguísticas. No primeiro deles, ao se discutirem procedimentos que deveriam ser adotados para a organização de novos bancos de dados, faz-se um breve retrospecto dos bancos de dados já constituídos, para, então, se apresentarem sugestões relativas à coleta e à expansão de corpora de diferentes comunidades de fala e de diferentes comunidades de prática. Além disso, o artigo também apresenta os critérios de constituição dos seguintes bancos de dados de fala do Nordeste: o Banco de dados da Fala Culta de Itabaiana, o banco de dados "Falares Sergipanos" e o banco de dados "Fala - Natal". O segundo artigo, além de discutir critérios que definem a construção da amostra do GESOL-USP, ${ }^{3}$ traça um panorama dos trabalhos que se têm desenvolvido a partir dos dados já coletados pelo Grupo, que tem como objetivo geral inserir a cidade de São Paulo e o paulistano no mapa sociolinguístico do Brasil.

Menos voltados para discussões de caráter metodológico, os seis próximos artigos cuidam mais de expor resultados de análises de fenômenos específicos, investigados de acordo com a metodologia da sociolinguística variacionista. A partir de banco de dados produzido no interior do $\mathrm{PROBRAVO}^{4}$, o primeiro artigo apresenta uma descrição sociolinguística que prioriza a variação de vogais médias pretônicas, de vogais postônicas mediais e da nasalidade alofônica presentes na variedade do português falado na Amazônia paraense. Os resultados reforçam a hipótese de que o Pará compreenderia uma ilha dialetal entre os dialetos do Norte do Brasil. Focando o português falado no extremo oposto do país, mas ainda tratando de variação fonológica, o próximo artigo analisa a palatalização variável das plosivas alveolares em amostras de fala da comunidade de Flores da Cunha, armazenadas no BDSer. ${ }^{5} \mathrm{~A}$ análise revela a progressão da palatalização na

\footnotetext{
Atlas Linguístico do Brasil.

Grupo de Estudos e Pesquisas em Sociolinguística da USP.

4 Grupo de Pesquisa de Descrição Sócio-Histórica das Vogais (do Brasil) <http://relin.letras.ufmg.br/probravo>.

5 Banco de Dados de Fala da Serra Gaúcha, da Universidade de Caxias do Sul.
} 
comunidade em função de condicionantes de natureza tanto linguística quanto social (jovens, vogal alta fonológica, habitantes de zona urbana e consoante-alvo desvozeada), evidenciando que a alta densidade da rede social, nucleada por informantes de grupos etários mais velhos, refreia a palatalização.

Ainda nessa linha de descrição e análise de fenômenos específicos, mas com objetivos e ênfases diferenciados, os três próximos artigos se debruçam sobre fenômenos variáveis de ordem morfossintática. O primeiro, baseado em amostras de fala do Banco de Dados Iboruna, ${ }^{6}$ apresenta comparações interdialetais para três diferentes fenômenos variáveis, e constata, na fala do interior paulista: (i) a acentuada frequência de uso de a gente em detrimento de nós, com influência apenas da variável faixa etária; (ii) índices bastante elevados de concordância verbal com nós; (iii) regra semicategórica na concordância verbal com a gente; (iv) índices acima dos 70\%, na concordância verbal de 3PP. Para essa mesma variedade do portugês, discute-se, no artigo seguinte, a natureza de motivações funcionais e formais na explanação de fenômenos variáveis, a partir da investigação da marcação de número em SNs e SAs em posição de predicativo. As análises mostram que princípios funcionais (como o de Economia e de Condição de Distintividade) atuam na marcação de pluralidade, mas não com força suficiente para reger todo o processo; por outro lado, motivações formais, gerenciadas pelo Princípio de Paralelismo Formal, também influenciam significativamente a marcação explícita de pluralidade nos dois fenômenos. Assim como ocorre com as motivações funcionais, as formais não atuam categoricamente de modo a governar sozinhas o fenômeno, como têm mostrado os estudos de outras variedades.

No terceiro artigo desse último agrupamento, são analisadas a concordância nominal de número e a concordância verbal de terceira pessoa do plural em variedades urbanas do Português Europeu, do Português do Brasil e do Português de São Tomé. Para o Português Europeu, os dados revelam tratar-se, em termos laboviano, de regra categórica, no que se refere à concordância nominal, e semicategórica, no que se refere à verbal; no Português do Brasil e no Português de São Tomé, ambas as regras são variáveis.

Fecha o grupo dos fenômenos variáveis específicos e, por fim, o volume como um todo, artigo que, advindo doVALPB ${ }^{7}$, enfoca três processos fonológicos na oralização do texto escrito e sua interferência no processo de leitura: a ditongação, a monotongação e o apagamento da oclusiva 'd' no grupo -ndo. Dentre os fenômenos variáveis analisados, as formas não estigmatizadas apresentaram maior

\footnotetext{
O Banco de Dados Iboruna (= rio preto, em Tupi), constituído pelo Projeto ALIP (Amostra Linguística do Interior Paulista) entre 2004 e 2007, compõe-se de dois tipos de amostras de fala: a primeira, coletada de acordo com os critérios da Sociolinguística laboviana constitui a Amostra Censo, e a segunda, coletada secretamente em contextos interacionais livres, sem controle de qualquer variável social, constitui a Amostra de Interação. Cf. Rúbio e Gonçalves, neste volume

7 Variação Linguística no Estado da Paraíba.
} 
índice de ocorrência, e sua realização não traz, em geral, influência negativa no desempenho da leitura por parte dos alunos. As formas estigmatizadas, como mais propensas à correção pelo professor, ocorrem com menos frequência e tendem a ser menos usadas com o avanço da escolaridade.

Feitas as apresentações, tentemos, a partir de agora, estabelecer relações possíveis entre os conteúdos dos artigos, considerando três eixos: (i) os pressupostos teóricos compartilhados pelos diferentes grupos de pesquisa; (ii) os seus principais resultados e (iii) as preocupações metodológicas dos autores em relação ao fazer científico nos campos da Sociolinguística e da Dialetologia.

Uma característica importante deste volume temático é o fato de que todos os trabalhos compartilham pressupostos teórico-metodológicos gerais da sociolinguística variacionista, tal como o conceito de regra variável que emerge dos estudos variacionistas e que:

representou um avanço teórico importante para a ciência linguística, na medida em que incorpora à gramática a sistematicidade estrutural e social do componente variável da língua. O investimento constante nessa vertente de estudos [...] tem acumulado evidências consideráveis sobre (a) a configuração de vários fenômenos variáveis no português falado [...], (b) as restrições que operam sobre cada um deles, (c) a ação regular dos diferentes princípios que subjazem ao uso das formas variáveis e que regulam a implementação da mudança na comunidade de fala e no indivíduo. ${ }^{8}$

Além disso, é possível dizer que muitos trabalhos do volume compartilham dos princípios elaborados a partir dos resultados das pesquisas pioneiras do Projeto PEUL, no que diz respeito às trajetórias de algumas variantes linguísticas do PB: "(a) contínua implementação de variantes linguísticas; (b) estabilidade da variação e (c) retração de uma variante em contextos particulares". ${ }^{9}$ Questão importante discutida ao longo de vários dos artigos é a sistematicidade no controle estrutural da variação. No entanto, variados fenômenos têm ressaltado a importância de princípios de natureza funcional. Na direção desse posicionamento, temos a apresentação de uma perspectiva na qual as gramáticas das línguas apresentam uma natureza parcialmente sistemática, o que colabora para uma compreensão da natureza da variação linguística:

As gramáticas são, por um lado, parcialmente autônomas, e daí sistemas, e, por outro, parcialmente suscetíveis a pressões externas ao sistema, daí adaptativas. Segundo Du Bois (1985), essa distinção é metodologicamente útil apenas se dermos pleno reconhecimento

8 Cf. Paiva e Paredes e Silva, neste volume.

9 Cf. Paiva e Paredes e Silva, neste volume. 
à existência de motivações em competição e desenvolvermos um arcabouço teórico que, inicialmente, descreva e analise a interação das motivações com contextos específicos e, posteriormente, seja capaz de prever a resolução da competição entre elas. ${ }^{10}$

Essa concepção favorece um tipo de interpretação sobre as relações entre os fatores internos e os fatores externos que pressionam/constituem/formatam a variação linguística:

Dizer que a língua é adaptativa por responder a pressões do contexto externo, implica de pronto rejeitar a teoria do estruturalismo autônomo, que é limitada na tentativa de explicar a estruturação de uma língua, por reconhecer apenas forças motivadoras internas. Dizer, por outro lado, que a língua é um sistema, e que, como tal, tem certo grau de continuidade de existência, implica rejeitar o arcabouço teórico do funcionalismo transparente, que falha em explicar o fato de que categorias gramaticais podem ser preservadas, por assim dizer, numa forma mais ou menos congelada. Mais importante ainda que isso talvez, ele falha em construir apropriadamente o aspecto interno mais fundamental da gramática, o processo de gramaticalização em si mesmo. ${ }^{11}$

Vemos, então, que esse número temático possibilita a leitura de autores que, ao mesmo tempo em que compartilham de alguns pressupostos mais gerais, também podem divergir sobre a maneira de ver a interação entre fatores internos e externos na explicação de fenômenos linguísticos variáveis.

Ao longo do volume, é possível observar ainda a complementariedade entre os resultados de pesquisa apresentados. Não poderíamos deixar de trazer aqui os resultados das várias pesquisas sobre o clássico fenômeno da concordância, cuja importância para a compreensão das diferenças entre variedades do Português pode ser assim resumida:

\footnotetext{
Um dos temas mais focalizados no âmbito do Português, sobretudo no que se refere à variedade brasileira, a concordância nominal e verbal suscita, ainda, grande interesse em virtude não só de fatores linguísticos que se vêm mostrando recorrentes em diversos estudos, mas também de implicações sócio-histórico-culturais para a caracterização das variedades do Português. ${ }^{12}$
}

São exatamente as implicações de natureza sócio-histórico-cultural para a caracterização da variedade do PB que podem ser observadas na formulação dos resultados de pesquisa abaixo:

10 Cf. Camacho e Salomão, neste volume.

11 Cf. Camacho e Salomão, neste volume.

12 Cf. Brandão e Vieira, neste volume. 
Os primeiros estudos em tempo real de curta duração fornecem indícios claros de aumento das marcas de concordância verbal e nominal tanto no indivíduo como na comunidade de fala carioca (NARO; SCHERRE, 2003, 2010). Reexaminando essa tendência mais recentemente (SCHERRE; NARO, 2011), os dois autores retomam a questão do efeito de variáveis sociais sobre a presença das marcas de concordância entre verbo e sujeito e em todos os elementos do SN, na comunidade de fala carioca, com o intuito de evidenciar como os grupos de falantes mudam no tempo.

(...) Usando os agrupamentos de idade projetados no lugar das faixas etárias originalmente estabelecidas, Naro \& Scherre (2011) puderam, então, ver mais claramente as mudanças dentro da comunidade de fala e confirmar tanto o modelo de fluxos e contrafluxos, proposto inicialmente por Naro (1981) e retomado por Naro (1999) e Naro \& Scherre (2010), como a ampliação da aquisição da concordância do plano individual para a comunidade como um todo. Testemunha-se, assim, a previsão de Naro (op. cit.), baseada na análise da Amostra MOBRAL (NARO, 1981), no que diz respeito ao efeito da variável orientação cultural sobre a concordância verbal. Os falantes que se identificavam com valores da classe média, os de orientação vicária, favoreciam mais a concordância verbal. Este traço foi mensurado por meio do tipo de programa de televisão visto, no caso, as novelas. Assim, Naro (1981) levanta a hipótese de que este efeito no plano individual poderia ser ampliado para a comunidade por meio das faixas etárias mais jovens, que é o que estamos observando nos dados do PEUL da década de 2000. ${ }^{13}$

Um outro trabalho procura comparar achados mais recentes quando da comparação entre três variedades do português ( $\mathrm{PB}$, português europeu e português de SãoTomé e Príncipe) com os achados anteriores sobre o fenômeno da concordância, fazendo uma breve discussão sobre o papel desse fenômeno na formulação de parâmetros gramaticais que caracterizem cada variedade do Português:

Embora não constitua objetivo do presente artigo ${ }^{14}$, é fundamental que se comparem os dados da presente pesquisa com os de outras investigações sociolinguísticas com amostras do PE, sobretudo no âmbito do sintagma verbal. Trabalhos como os deVarejão (2006) e Monguilhot (2010) registram percentuais gerais de não marcação mais altos do que os verificados nesta pesquisa [...] que permitiriam postular a existência de uma regra variável em determinadas variedades do PE. Por ora, uma observação preliminar desses trabalhos sugere que tenha havido diferença tanto na coleta de dados considerados variáveis, quanto na interpretação de determinadas estruturas como reveladoras de falta de concordância.

Nesse sentido, considera-se apropriada a hipótese de Naro \& Scherre (2007, p. 85) da existência, mesmo no Português Europeu contemporâneo, de padrões variáveis em diversas regiões de Portugal: [...] É preciso ter

13 Cf. Paiva e Paredes Silva, neste volume.

14 Cf. Brandão e Vieira, neste volume. 
claro, por exemplo, que não se dispõe de trabalhos variacionistas baseados em amostras do PE.

(...) Voltando aos dados da presente pesquisa, há indícios de que é a atuação de determinados fatores externos que acelera ou detém a implementação das restrições linguísticas. Nas realidades brasileira e são-tomense, ao que tudo indica, o valor social que se atribui à não concordância seria compatível com um estereótipo (nos termos de Labov (1972)) ou, na melhor das hipóteses, com um marcador. Por essa razão, o fenômeno variável funciona como nítido identificador do perfil social do usuário da língua. No PST - que configura um caso de variedade do português em formação, com normas objetivas ainda não totalmente definidas e assumidas pelos diferentes grupos de falantes -, sabe-se que dominar a concordância segundo a norma culta que lhe serve de modelo, a do Português Europeu, seria um dos índices de identificação de pleno domínio da Língua Portuguesa. No PB, ao contrário, o uso ou não da concordância canônica é uma opção que está claramente no nível de consciência dos indivíduos, de modo que é interpretado e funciona como forte traço caracterizador de classes sociais. Na realidade europeia, os dados desta pesquisa não permitem inferir diferença de comportamento vinculada a qualquer variável social, o que faz crer que a concordância pode constituir um parâmetro gramatical naturalmente assumido pelos falantes.

Se nos voltamos para as descrições recentes do português paulista, vislumbramos resultados interessantes: o primeiro mostra a interação entre motivações internas e externas, fundamentais para a compreensão da marcação de número em estruturas predicativas:

A atuação do Princípio de Paralelismo Formal, na variedade estudada, sofre severa restrição da condição social dos usuários da variedade, especialmente, a formação escolar; desse modo, ao menos no que tange à variedade investigada, não é possível dar a esse princípio o poder explanatório que lhe atribui Labov (1994), isto é, o de que a pluralidade tem uma motivação essencialmente interna, derivada da própria configuração formal do sistema gramatical, que governa, neste caso específico, a variedade riopretense. Por essa razão, a explicação mais plausível para a marcação de pluralidade nos predicativos é a de que há motivações em competição, nos termos de Du Bois (1985) e é a marcação de pluralidade o "bem limitado", pelo qual forças múltiplas, as motivações formais ou internas e funcionais ou externas, competem entre si. ${ }^{15}$

O segundo, sumarizado no quadro reproduzido abaixo, revela o comportamento da concordância verbal e da alternância pronominal na fala do interior paulista em consonância com resultados de pesquisa sobre outras variedades do PB.

15 Cf. Camacho e Salomão, neste volume. 
Quadro 7: Características dos fenômenos variáveis relacionados à concordância verbal e à alternância pronominal no português brasileiro do interior paulista. ${ }^{16}$

\begin{tabular}{|c|c|}
\hline \multirow[b]{2}{*}{ FENÔMENOS } & $\begin{array}{l}\text { PORTUGUES BRASILEIRO DO } \\
\text { INTERIOR PAULISTA } \\
\text { BANCO DE DADOS IBORUNA }\end{array}$ \\
\hline & COMPORTAMENTO / VARIAVEIS ATUANTES \\
\hline \multirow{2}{*}{$\begin{array}{l}\text { ALTERNANCIA } \\
\text { PRONOMINAL } \\
\text { DE 1a PESSOA } \\
\text { DO PLURAL }\end{array}$} & Variável \\
\hline & $\begin{array}{c}\text { paralelismo discursivo > saliência fônica > grau de } \\
\text { determinação do sujeito > tempo e modo verbal > } \\
\text { escolaridade > faixa etária. }\end{array}$ \\
\hline $\begin{array}{l}\text { CONCORDANCIA } \\
\text { VERBAL } \\
\text { COM NÓS }\end{array}$ & $\begin{array}{l}\text { Variável } \\
\text { saliência fônica > paralelismo discursivo > explicitude do } \\
\text { sujeito > escolaridade > faixa etária. }\end{array}$ \\
\hline \multirow{2}{*}{$\begin{array}{l}\text { CONCORDANCIA } \\
\text { VERBAL } \\
\text { COM A GENTE }\end{array}$} & Semicategórica \\
\hline & $\begin{array}{c}\text { paralelismo discursivo }>\text { saliência fônica }>\text { grau de } \\
\text { determinação do sujeito }>\text { explicitude do sujeito }>\text { faixa } \\
\text { etária. }\end{array}$ \\
\hline \multirow{2}{*}{$\begin{array}{c}\text { CONCORDANCIA } \\
\text { VERBAL } \\
\text { DE 3a PESSOA } \\
\text { DO PLURAL }\end{array}$} & Variável \\
\hline & $\begin{array}{c}\text { paralelismo discursivo > saliência fônica > paralelismo } \\
\text { oracional }>\text { traço semântico do sujeito > posição do sujeito } \\
\text { > escolaridade > faixa etária > gênero. }\end{array}$ \\
\hline
\end{tabular}

Como vimos, o debate instaurado pelos diferentes artigos sobre esse tema específico da concordância reforça a tese do início dessa apresentação: a de que o campo dos estudos sociolinguísticos e dialetológicos no Brasil encontra-se em "efervescência", ${ }^{17}$ produzindo múltiplas e panorâmicas fotografias da realidade sociolinguística no Brasil e de outras comunidades de fala de Língua Portuguesa.

Não é nosso objetivo nesta apresentação elencar todos os temas abordados ao longo dos artigos, mas vale a pena registrar a recorrência de alguns deles na agenda da pesquisa sociolinguística e dialetológica brasileira. No plano fonológico, destacam-se: a supressão da semivogal [y] no ditongo decrescente [ey]; o alçamento de vogais pretônicas, de vogais postônicas finais e não finais; o apagamento da vogal postônica não final; a redução de ditongos nasais átonos; a

16 Cf. Rúbio e Gonçalves, neste volume.

17 Ver, a esse respeito, caderno de resumos do II Congresso Internacional de Dialetologia e Sociolinguística, realizado em setembro último, na Universidade Federal do Pará, sob o tema "Diversidade linguística e Políticas de ensino", tendo como homenageada a Profa. Dra. Vandersi de Andrade Aguilera, coautora neste volume temático. O congresso teve 1.000 (hum mil) inscritos. (Cf. http://www.cids.ufpa.br. Acesso em out.2012). 
epêntese vocálica em grupos consonantais; fenômenos de juntura vocabular, como degeminação, elisão e ditongação; a variação de líquidas laterais, de vibrantes prevocálicas, intervocálicas e pós-vocálicas, de oclusivas dentais /t/ e /d/, diante de [i], de /s/ posvocálico; a monotongação de ditongos decrescentes; a ditongação em contextos seguidos de sibilantes; a haplologia sintática em sequência de sílabas com /t/ e /d/ subjacentes; a distribuição do <s> em coda silábica. No nível morfossintático, destacam-se: a realização variável da preposição núcleo dos complementos dativos; a variação no preenchimento da posição de sujeito e de objeto direto anafórico; a alternância pronominal entre nós e a gente, entre você/cê/ocê e entre tu e você; a alternância entre futuro do pretérito e pretérito imperfeito; a expressão variável do futuro do presente; a redução de gerúndio; a variação sintática das orações adverbiais finais; a expressão gramatical do imperativo; a alternância indicativo/subjuntivo; a ausência/presença de artigo diante de antropônimos e de possessivos; o uso variável da concordância verbal e nominal, dentre tantos outros.

É também importante ressaltar que há, ao longo de todo este volume temático, uma constante discussão sobre os métodos de trabalho de campo e sobre as relações entre abordagens quantitativas e qualitativas no tratamento da variação linguística. Os convergentes e/ou divergentes posicionamentos em relação ao tema da concordância já indiciam essa condição inerente aos sociolinguistas: a de busca incansável do "melhor método" de conduzir e de formatar um estudo sobre determinado fenômeno variável. É nesse sentido, por exemplo, que todos os artigos acabam, de uma forma ou de outra, tematizando questões metodológicas. Uma primeira questão tematizada é a própria validade da construção de bancos de dados:

A documentação da língua falada é fundamental para que os estudiosos da linguagem tenham onde buscar comprovação empírica para suas hipóteses e teorias. Nesse sentido, parece-nos que um banco de dados de fala tenha relevância implícita, independentemente da metodologia de coleta e de organização dos dados. Entretanto, dado que as abordagens em termos de coleta de dados e de foco da investigação linguística vão se aperfeiçoando e se modificando continuamente, cremos que cabe a discussão sobre a questão da relevância de um banco (...). ${ }^{18}$

Uma segunda questão tematizada é a relação entre os métodos de coleta dialetológicos e os métodos de coleta sociolinguísticos:

A "nouvelle géolinguistique", a que se refere Thun, busca unir ao princípio da diatopia, pelo qual se vem regendo a Dialetologia desde os seus primórdios, princípios sociolinguísticos que, juntando-se ao primeiro, vão ensejar cartas linguísticas que permitem ao leitor não só saber onde se diz tal coisa, mas que tipo de falante - homem-mulher, jovem-velho, escolarizado-não escolarizado — é responsável por aquele enunciado.

18 Cf. Collischonn e Monaretto, neste volume. 
Para alcançar a abrangência desejada, de acordo com os parâmetros metodológicos da Geolinguística Pluridimensional, o Projeto ALiB insere, ao lado da pesquisa da variação diatópica, também a de outras dimensões variacionais, como a diageracional, a diagenérica, a diastrática, a diafásica e a diarreferencial.

Do ponto de vista diatópico, a rede, constituída de 250 pontos, distribuise, geograficamente, por todo o território nacional, levando em conta a densidade demográfica de cada região e de cada Estado, com os ajustes necessários nos casos de áreas com densidade muito baixa, como a região norte e centro-oeste, ou demasiadamente elevada, como na região sudeste, principalmente em São Paulo. E, na seleção das localidades, além da distribuição espacial, consideram-se a importância de cada uma delas na região e no Estado e dados de sua formação, além de limites interestaduais e internacionais. Incluem-se cidades de grande e médio porte, inclusive as capitais de Estado — à exceção do Distrito Federal e de Palmas, no Tocantins, cidades de formação relativamente recente nas quais ainda não se pode dispor de três gerações nascidas e criadas na área e com idade requerida para a seleção de informantes."

Para atender à variação social, os informantes, em número de quatro em cada ponto - exceto nas capitais de Estado, onde são oito -, estratificam-se quanto ao gênero - quinhentos e cinquenta homens e quinhentas e cinquenta mulheres - à faixa etária - a primeira de 18 a 30 anos e a segunda, de 50 a 65 anos - e, nas capitais, ao nível de escolaridade - fundamental e universitário. ${ }^{19}$

Uma terceira questão tematizada é a da inserção de uma parte significativa dos trabalhos sociolinguísticos brasileiros no interior da chamada primeira onda de estudos linguísticos ("a era dos inquéritos"):

No Brasil, os estudos quantitativos com bancos de dados estratificados de acordo com características sociodemográficas amplas têm se consolidado como modelo hegemônico, com os bancos de dados do Programa de Estudos sobre o Uso da Língua (PEUL) [...] A partir deste, foram replicados projetos em diferentes regiões do Brasil, com adaptações em sua metodologia [...] Esse tipo de banco de dados possibilita captar tendências amplas de variação e mudança em uma comunidade de fala. Implica, entretanto, a homogeneização da amostra [...] É importante destacar que a elaboração desses corpora permitiu a descrição do português brasileiro em diferentes aspectos linguísticos e considerando distintas variedades. De algum modo, têm-se uma descrição da variação na(s) gramática(s) do português do Brasil envolvendo diferentes fenômenos e a correlação destes com variáveis sociais. ${ }^{20}$

19 Cf. Cardoso e Mota, neste volume.

20 Cf. Freitag, Martins e Tavares, neste volume. 
Na comparação entre os estudos das primeira e segunda ondas com os da terceira onda, chama-se atenção para o fato de que os primeiros "têm como foco a descrição da estrutura - um retrato estático". Já os estudos de terceira onda "incorporam a dinamicidade da estrutura"; assim, não se estaria "negando a estrutura, mas sim enfatizando o papel da estrutura no condicionamento da prática paralelamente ao papel da prática na produção e reprodução da estrutura, a fim de captar com mais detalhes a dinâmica do valor social das variáveis". ${ }^{21}$ Vale a pena acompanhar a argumentação abaixo no que diz respeito à necessidade de ser revista a prática brasileira de constituição de banco de dados sociolinguísticos:

Como vimos destacando, bancos de dados linguísticos têm sido fonte privilegiada para a descrição do português brasileiro e a tendência recente dos estudos de terceira onda ratifica sua importância para apontarem tendências linguísticas na comunidade. Seguindo as premissas da confiabilidade e da intersubjetividade (BAILEY; TILLERY, 2004), para dar continuidade a essa prática produtiva, novos bancos de dados precisam conservar minimamente as estratificações dos bancos de dados já existentes, pois a comparação de dados em tempo real permite análises mais acuradas com estudos de painel e de tendência (LABOV, 2001). Assim, as variáveis demográficas amplas - sexo, idade, escolarização etc. - precisam continuar a ser controladas nas novas coletas e nas novas amostras constituídas; é desejável, entretanto, que as novas coletas aprimorem o controle do falante, suas características individuais e de práticas, de modo a permitir que se construa um perfil social que contemple indicadores sociodemográficos mais amplos e abstratos. ${ }^{22}$

Como vimos até aqui, muitas e complexas são as questões envolvidas na produção de um conhecimento sociolinguístico e/ou dialetológico. Nessa apresentação, procuramos fazer nosso leitor reconhecer aquelas que estão na base de nossas preocupações: Quais fenômenos variáveis estudar? De que forma fazer isso? Com que hipóteses? Com que ferramentas? A nosso ver, ao fim e ao cabo, o mais importante é o fato de que este volume conseguiu reunir um conjunto bastante representativo dos trabalhos dos dois campos acima referidos. Talvez sejam os campos de estudos, junto com o campo da antropologia, que mais coloque em relação direta e momentaneamente próxima (com todas as injunções éticas que disso decorrem) o pesquisador e o pesquisado. Por isso mesmo é que talvez tenham se desenvolvido, justamente nesses campos, tantos instrumentos específicos de coleta e registro de dados, tantos cuidados com a forma de se apresentar os resultados das pesquisas, tanta discussão a respeito da melhor maneira de "tratar" os dados. No entanto, não deixa de ser encantador e

21 Cf. Freitag, Martins e Tavares, neste volume.

22 Cf. Freitag, Martins e Tavares, neste volume. 
rico para nós, pesquisadores, o carinho e a atenção que podemos receber, mesmo que apenas momentaneamente, daqueles que são nossos sujeitos de pesquisa, cujas falas se transformarão em loci de observação e de rigoroso controle. É com o depoimento abaixo que já vamos nos encaminhando para o fim desta apresentação, numa homenagem a todos aqueles que contribuem tanto para que o nosso trabalho possa ser feito e para que as fotografias, uma vez reveladas, possam se revestir de algum significado social mais concreto para eles e para toda a comunidade.

Na linha da compreensão do projeto, outro inquérito vem para ilustração. Fazia-se a documentação do informante faixa etária II, portanto dos 50 anos para cima, homem de escolaridade fundamental. Foi entrevistado na sala da sua casa, casa simples nos arredores de Recife, ato presenciado, além dos partícipes - o informante, a inquiridora e a auxiliar de pesquisa -, pela sua esposa. A documentação dos dados corria muito bem, acabava-se de fazer a aplicação do OFF, do OSL e do OMS — como se sabe, uma espécie de pingue-pongue em que o inquiridor pergunta e o informante responde - e passava-se às questões semidirigidas, nas quais se pede ao informante o relato de fatos sobre temas orientados. Naquele exato momento, se desgruda da sala a esposa do informante que volta, incontinente, com um sanduíche quente e um suco de laranja, e sussurra ao ouvido da inquiridora: "Estou vendo que agora é ele que fala mais e aí a senhora pode comer uma coisinha". Compreensão da pesquisa, respeito ao método, entendimento perfeito da mecânica do interrogatório linguístico, uma solidariedade ilimitada ao trabalho dialetal. É preciso que se diga: acabado o inquérito, ao entrarem no táxi inquiridora e auxiliar, aquela não pode conter as lágrimas da emoção seguradas no final da gravação. São essas e outras lições que o trabalho de campo permite ao pesquisador aprender ou reafirmar o seu aprendizado". ${ }^{23}$

E, para finalizar, então, não podemos deixar de registrar aqui o ano do jubileu de ouro da Alfa - Revista de Linguística, ocasião, para nós, de alegria e honra imensas por nos ter sido concedida a oportunidade de reunir neste volume temático a contribuição de 43 pesquisadores e de 23 pareceristas anônimos das mais diferentes partes do Brasil, números que, seguramente, refletem a intensa movimentação científica do campo dos estudos sociolinguísticos e dialetológicos do/no Brasil.

Parabéns à Alfa - Revista de Linguística! Parabéns a todos os autores reunidos neste volume!

23 Cardoso e Mota, neste volume. 